\title{
The Results of Tests of the MICE Spectrometer Solenoids
}

\author{
S. P. Virostek and M A Green Member IEEE
}

\begin{abstract}
The Muon Ionization Cooling Experiment (MICE) spectrometer solenoid magnets will be the first magnets to be installed within the MICE cooling channel. The spectrometer magnets are the largest magnets in both mass and surface area within the MICE cooling channel. Like all of the other magnets in MICE, the spectrometer solenoids are kept cold using $1.5 \mathrm{~W}$ (at $4.2 \mathrm{~K}$ ) pulse tube coolers. The MICE spectrometer solenoid is quite possibly the largest magnet that has been cooled using small coolers. Two spectrometer magnets have been built and tested. This report discusses the results of current and cooler tests of both magnets.
\end{abstract}

Index Terms-Solenoid Magnet Tests and Pulse Tube Cooler

\section{INTRODUCTION}

$\mathrm{T}$ he MICE spectrometer solenoids will provide a uniform magnetic field for the five plane scintillating fiber trackers that are within the $400 \mathrm{~mm}$ warm bore of the magnet [1]. The trackers are used to analyze the muon beam emittance change in the cooling channel.

The spectrometer solenoid vacuum vessel is $2735-\mathrm{mm}$ long and 1404-mm in outside diameter [2]. On top of the round vacuum chamber is a service turret that contains the coolers and the leads. The 2515-mm long cold mass consists of five superconducting coils. There are two $200-\mathrm{mm}$ long match coils that match the muon beam from the absorber focus coil module into the tracker section of the spectrometer magnet.

The tracker section of the magnet consists of two 110-mm long coils at the ends of a long solenoid that is 1314-mm long. The three coils will generate a uniform field $(\sim \pm 0.3$ percent) over a length of $1000 \mathrm{~mm}$ and in a diameter that is $300 \mathrm{~mm}$. The two match coils and the three coil tracker set are powered by three $300 \mathrm{~A}$ power supplies. The two $110 \mathrm{~mm}$-long end coils are tuned using a pair of 60 A power supplies [3].

The magnet is designed to be cooled using three PT-415 pulse tube coolers that develop $50 \mathrm{~W}$ at $55 \mathrm{~K}$ on the $1^{\text {st }}$ stage and $1.5 \mathrm{~W}$ at $4.2 \mathrm{~K}$ on the $2^{\text {nd }}$ stage. Since the two magnets will be shipped long distances, drop-in coolers are used [4]. These coolers can be removed during shipment from the vendor to Fermilab (outside of Chicago) and from Fermilab to the Rutherford Appleton Laboratory in the United Kingdom.

Manuscript received 20 October 2009. This work was also supported by the Office of Science of the US Department of Energy under DOE contract DE-AC-02-05CH11231. M. A. Green and S. P Virostek are from the Lawrence Berkeley National Laboratory, Berkeley CA 94720, USA (M. A. Green's contact e-mail is: magreen@lbl.gov).

\section{BASIC Design OF THE SPECTROMETER MAGNETS}

The spectrometer magnet is wound Nb-Ti conductor with a $\mathrm{Cu}$ to $\mathrm{Nb}-\mathrm{Ti}$ ratio of four. The conductor has 222 filaments that are $41-\mu \mathrm{m}$ in diameter. The dimensions of the insulated conductor are 1.65 by $1.00 \mathrm{~mm}$. The conductor twist pitch is $\sim 19 \mathrm{~mm}$. Four billets of the conductor were delivered in six pieces that ranged in length from $11 \mathrm{~km}$ to $36 \mathrm{~km}$.

All five coils are wound on a single 6061-T6-aluminum mandrel. None of the ten-spectrometer solenoid coils (both magnets) have splices in them. The cryostat consists of a liquid helium vessel, an $80 \mathrm{~K}$ thermal shield, cold mass supports designed for $500 \mathrm{kN}$ in the axial direction and a stainless steel vacuum vessel. A schematic representation of the magnet (not drawn to scale) is shown in Fig. 1.

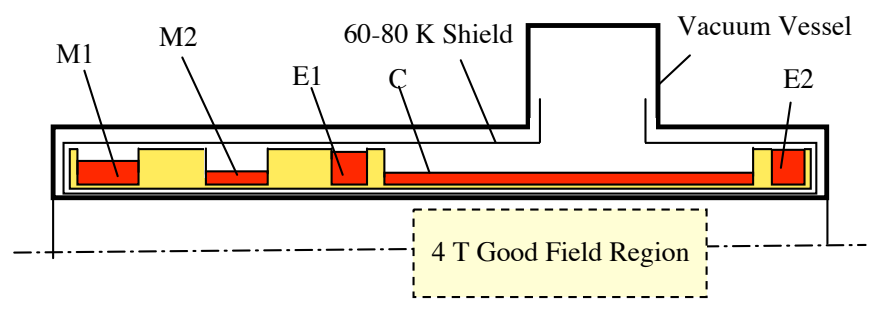

Fig.1 A Schematic Cross-section of the MICE Spectrometer Solenoid

The two magnets were completed a year apart. The fabrication of the second magnet was affected by the tests of the first magnet, which is shown in Fig. 2. TABLE 2 presents the as built dimensions of the second magnet. The two magnets are almost identical. The axial coil center locations are the same within 25 microns. The radial coil center locations of vary up to 350 microns. The second magnet center coil has eight more turns than the first magnet. From the standpoint of the beam, the magnets are identical [5] [6].

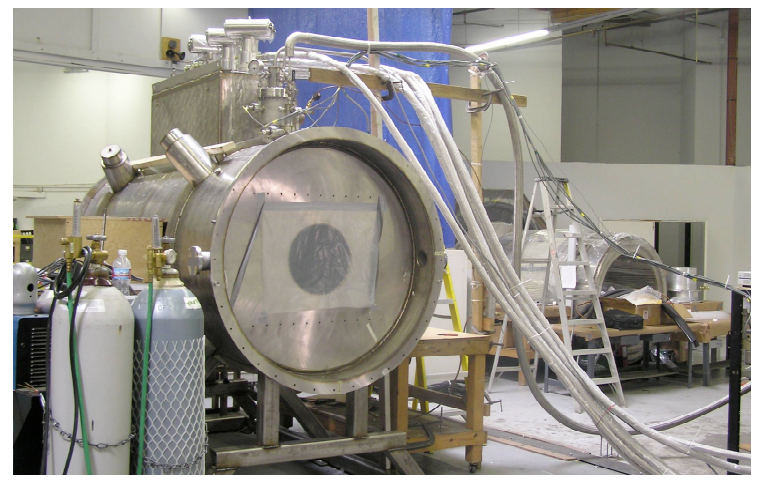

Fig.2. Spectrometer Solenoid 1 with its Three PT-415 Coolers in Operation 
Table 1. The As Built Parameters for the SeCond MiCE SPectrometer Solenoid [5]

\begin{tabular}{|c|c|c|c|c|c|}
\hline & Match 1 & Match 2 & End 1 & Center & End 2 \\
\hline Inner Coil Radius (mm) & 258 & 258 & 258 & 258 & 258 \\
\hline Coil Thickness (mm) & 46.165 & 30.925 & 60.905 & 22.125 & 67.783 \\
\hline Coil Length (mm) & 201.268 & 199.492 & 110.642 & 1314.30 & 110.642 \\
\hline Current Center Axial Position* (mm) & 124.00 & 564.00 & 964.00 & 1714.00 & 2464.00 \\
\hline Current Center Radial Position* (mm) & 281.083 & 273.463 & 288.453 & 269.063 & 291.891 \\
\hline Coil Average J $\left(\right.$ A mm² $\left.^{-2}\right)$ & 137.67 & 147.77 & 124.28 & 147.66 & 127.09 \\
\hline Number of layers per Coil & 42 & 28 & 56 & 20 & 62 \\
\hline Number of Turns per Layer & 115 & 114 & 64 & 768 & 64 \\
\hline Total Number of Turns & 4830 & 3192 & 3584 & 15360 & 3968 \\
\hline Design Current $(\mathrm{A})^{* *}$ & 264.83 & 285.60 & 233.68 & 275.52 & 240.21 \\
\hline Coil Self Inductance $(\mathrm{H})^{\wedge}$ & 12.0 & 5.0 & 9.0 & 40.0 & 11.3 \\
\hline Coil Stored Energy $(\mathrm{MJ})^{* *}$ & 0.42 & 0.20 & 0.26 & 1.55 & 0.32 \\
\hline Peak Field in Coil $(\mathrm{T})^{* *}$ & 5.30 & 4.32 & 5.68 & 4.24 & 5.86 \\
\hline Temperature Margin at $4.2 \mathrm{~K}(\mathrm{~K})^{* *}$ & $\sim 1.6$ & $\sim 1.8$ & $\sim 1.5$ & $\sim 2.0$ & $\sim 1.5$ \\
\hline
\end{tabular}

Fig. 3 shows a design case for the charging and the quench protection circuit for the matching section and three coil spectrometer section for a MICE spectrometer solenoid. Each match coil will be powered by a power supply that delivers $300 \mathrm{~A}$ at $10 \mathrm{~V}$. The magnet discharge will be through a diode pack. The three-coil spectrometer solenoids are connected in series using a single $300 \mathrm{~A}$ power supply that delivers a voltage up to $10 \mathrm{~V}$. The end coils E1 and E2 will be adjusted using a pair of power supplier that will deliver $60 \mathrm{~A}$ at $5 \mathrm{~V}$.

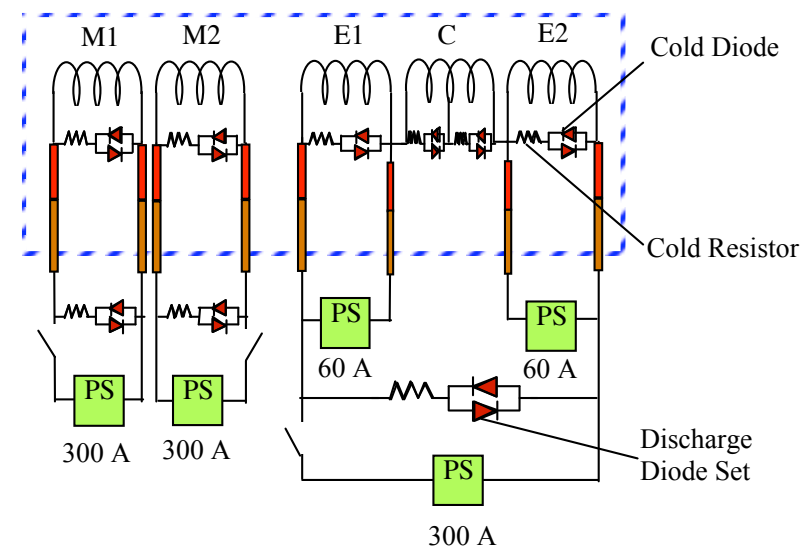

Fig.3 Quench protection circuit for the MICE spectrometer solenoids

The spectrometer magnet quench protection is passive. The two match coils each have back-to-back diodes and a resistor across them, which protect the coils in the event of a lead failure. The end coils E1 and E2 of the three-spectrometer coil set also have back-to-back diodes and a resistor across them. The center $(\mathrm{C})$ solenoid of the spectrometer solenoid set is sub-divided into two parts back-to-back diodes and a resistor across them. Thus the three-coil spectrometer section has a total of four sub-divisions. The four sub-divisions reduce the voltage to ground and protect the three-coil tracker section of the magnet in the event of a lead failure [7]. The hot spot temperature (particularly in the long center coil) is reduced by magnet quench back from the aluminum mandrel.

\section{THE RESULTS OF THE FIRST MAGNET TEST}

The first magnet was cooled down using liquid nitrogen and liquid helium in June 2008. The coolers were not turned on until the magnet reached $20 \mathrm{~K}$ using liquid helium. During the first magnet cool-down, liquid nitrogen was allowed to collect in the helium tank. The coil resistance was not monitored during the cool down. The liquid nitrogen was removed from the tank by injecting warm helium gas into the tank through the fill pipe and pumping the gasses from the tank. This proved to be a problem. In order to understand the problem, one should look at a schematic of how the coolers were connected to the helium tank of the first magnet (see Fig. 4).

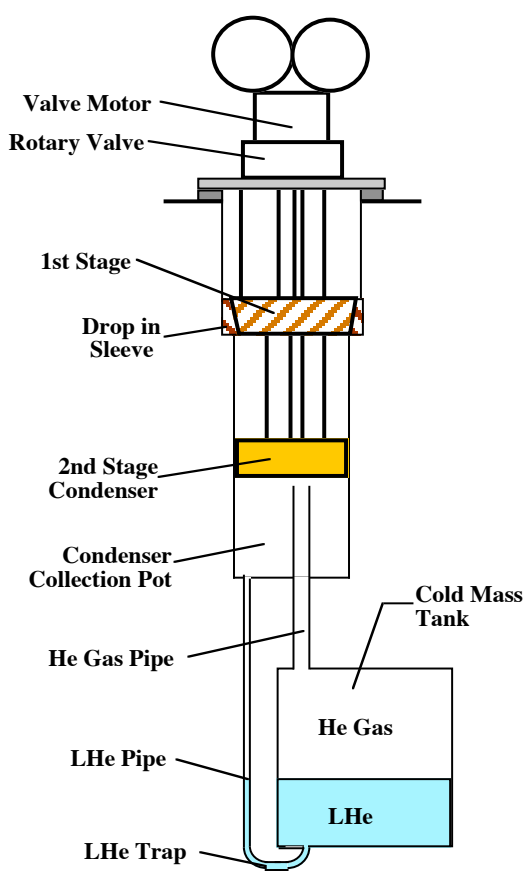

Fig. 4. A Schematic of the Connection of the PT-415 Coolers to the Magnet Helium Tank in the First MICE Spectrometer Solenoid. 
The coolers were used to cool the magnet shield and the cold mass support intercepts. The design shield and support intercept temperature is $\sim 70 \mathrm{~K}$. The shield took many days to cool down. It never got down its design temperature. The shield temperature near the cooler was $\sim 93 \mathrm{~K}$ while the ends reached about $108 \mathrm{~K}$. The magnet bore shield was probably $\sim 120 \mathrm{~K}$. The temperature of the copper plates, outside of the coolers, reached temperatures ranged from $55 \mathrm{~K}$ to $62 \mathrm{~K}$. The temperature on the copper plate on the top of the HTS leads furthest from the cooler reached about $61 \mathrm{~K}$ (w/o lead current). While the magnet shield temperature was abnormally high, the temperature at the top of the HTS leads seemed about correct.

As soon as the helium tank was filled, the magnet training started. For magnet training all five of the coils were connected in series. After a few quenches a current of 196 A (70 percent of design current) was reached. It was clear that the passive quench protection for the magnet was working very well. Quench back from the mandrel prevented the hot spot temperature from getting too high. Sub-division of the coil circuit with cold diodes and resistors prevented high voltages to ground from forming within the magnet.

Training was stopped because the coolers were not producing enough cooling to prevent helium boil-off from the magnet cryostat. The boil-ff rate was measured to be between 6 and $8 \mathrm{~L} \mathrm{hr}^{-1}$, which, suggests that the heat load into the cryostat was from 4.3 to $5.7 \mathrm{~W}$ more than the coolers were removing from the magnet. The fact that the shield and the cold mass intercepts were running too warm contributed to the added heat leak into the helium tank, but this could not account for the excess heat loads we were seeing.

Since there were no temperature sensors on the cooler first or second stages, it was not possible to determine exactly how much heat the coolers were actually removing from the magnet at any given time. The stainless steel can, which was just outside of the condenser, seemed to be too cold (from 3.3 to $3.9 \mathrm{~K}$ ). This suggested the cooler second stages were producing very little net refrigeration. It was estimated that the first stages of the three coolers were producing total cooling from 150 to $165 \mathrm{~W}$ [8].

When the magnet cold mass was warmed up to $90 \mathrm{~K}$ an extra burst of nitrogen gas was produced. This suggested that there was frozen nitrogen trapped in the stainless steel pipe that connected the condenser pot with the bottom of the cold mass 190-liter helium tank. When there was liquid nitrogen in the tank, the trap in this pipe was filled with liquid nitrogen. The act of pumping after purging with warm helium froze the nitrogen in the pipe and prevented helium from flowing from the condenser to the cold mass helium tank. The magnet was warmed above $80 \mathrm{~K}$ during the test and re-cooled with liquid helium, while the coolers were running. As a result, it is likely that the gas pipe leading to the tank was also plugged with nitrogen ice. The condenser became flooded with liquid helium. Thus there was no virtually refrigeration from the three coolers that could reach the magnet cryostat. It was clear that nitrogen in the tank was a problem. We decided to modify the cool down procedure and modify the second magnet so that cooling tubes from the coolers couldn't be blocked nitrogen ice.

\section{Changes in Magnet Number two}

A third cooler test was run to see if a drop in cooler condenser would operate dropping liquid helium from the condenser directly into the top of the cryostat helium tank, as is often done with MRI magnets. After a successful cooler test, the magnet was modified so that the coolers could recondense directly into the helium tank (see Fig. 5). A liquid nitrogen tank was attached directly to the outer shield of the magnet. The liquid nitrogen could be used to pre-cool the shield as well ensure that its temperature be lower. The connection between the coolers and shield was improved. Later analysis showed this didn't significantly reduce the $\Delta \mathrm{T}$ from the shield to the coolers. In addition, the insulation around the cold mass supports was improved, and more insulation was put between the cold mass and the shield.

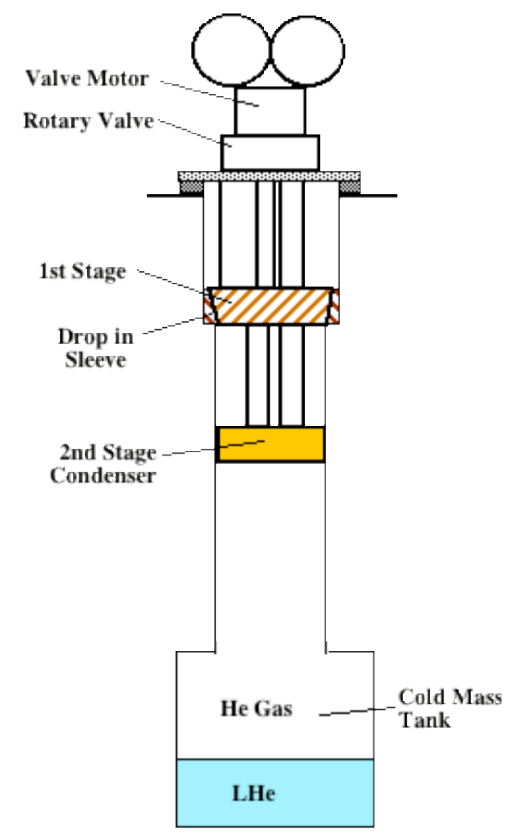

Fig. 5. A Schematic of the Connection of the PT-415 Coolers to the Magnet Helium Tank in the Second MICE Spectrometer Solenoid.

\section{The Results of the Second Magnet Test}

Magnet two was tested in June and July of 2009. The magnet was operated at $238 \mathrm{~A}$ ( $\sim 87$ percent of design current) with all five coils in series. The current test was stopped because the one HTS lead burned out.

The magnet shield ends were about $10 \mathrm{~K}$ warmer than they were for the first magnet test. At the same time, liquid nitrogen in the tank was being boiled at the rate of $0.75 \mathrm{~L} \mathrm{hr}^{-1}$ (an added $32 \mathrm{~W}$ ). The temperature near the cooler first-stages varied from $66 \mathrm{~K}$ to $74 \mathrm{~K}$. The $\Delta \mathrm{T}$ along the coolers and leads was greater than during the first test. The temperature at the far end of the leads was $81 \mathrm{~K}$, w/o current in the leads. The lead that burned out was at the $81 \mathrm{~K}$ end of the row of leads (see Fig 6). The 500-A HTS-110 leads used in the magnet, will carry $\sim 200 \mathrm{~A}$ at $81 \mathrm{~K}$. When the lead burned out, the quench protection diodes protected the magnet and caused it to quench. It appears that the heat into the shield and leads was excessive. The cooler stage 1 temperatures suggested that the heat load onto the first stages was $\sim 240 \mathrm{~W}$. 


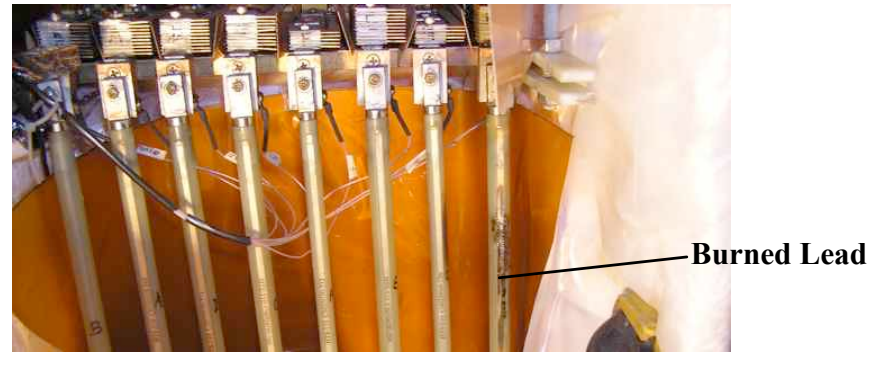

Fig. 6. The HTS leads in Magnet 2 after One Lead Burned Out

An alternative explanation for the excessive temperature at the tops of the HTS leads is that the first stage of one of the coolers was not connected to the copper thermal bus that is connected to the shield and the tops of the HTS leads. It appeared that all three coolers were producing cooling on their second stages, but a first stage disconnect can't be ruled out.

Despite, a high shield and intercept temperature (higher by over $30 \mathrm{~K}$ ) and a higher temperature at the top of the HTS leads (higher by $\sim 17 \mathrm{~K}$ ), the cooler second stages behaved well. At a helium tank pressure of 1.1 bars, the helium boil off rate was $0.125 \mathrm{~L} \mathrm{hr}^{-1}$ (an excessive heat leak of $\sim 0.09 \mathrm{~W}$ ). The measured cold mass temperature was consistent with the helium vessel pressure. If the shield and cooler first stage temperatures can be brought down, the three PT415 coolers can provide enough additional refrigeration to keep the second spectrometer magnet cold, even at full current.

The power supplies and the magnet rapid discharge system were tested. The behavior of the power supplies and their controllers was not fully understood. A rapid discharge varistor (diode) system was built to allow the spectrometer magnets to be discharged in the event of a power failure that would put the coolers out of commission [9], [10]. This would allow the magnet to be discharged fast enough to keep the HTS leads from burning out. When two match coils were discharged through the rapid discharge system, the discharge occurred without a problem. When a single match coil was discharged through the system, the magnet quenched. It appears that the coil quench was caused by excessive voltage across the quench protection diodes across the match coil.

\section{CONCLUSION, WHERE DO WE GO FROM HERE?}

The spectrometer solenoid for MICE is one of the largest magnets that has been cooled using small coolers. When one combines the physical size of the magnet $(2.7 \mathrm{~m}$ long by $1.4 \mathrm{~m}$ in diameter not including the service tower for the coolers, leads and $\mathrm{LN}_{2}$ tank) with a large cold mass (over 4 metric tons) and nearly 1000 A of conduction cooled lead pairs, one can see why it is difficult to keep the magnet cold using three PT415 coolers alone.

The cause of excess heat leak down the copper leads is being investigated. The temperature on the cold heads of all of the coolers will be measured so that we know if the temperature drop across the drop in joint is a factor in the excessive first stage temperature in magnet two.

A single stage Cryomech AL-330 GM cooler will be used to provide the extra cooling $(185 \mathrm{~W}$ at $55 \mathrm{~K}$ with $60 \mathrm{~Hz}$ power) that may be needed for the magnet shields and HTS leads. The cooler will provide cooling at the far end of the lead string, away from the three pulse tube coolers. The magnetic induction is low $(\sim 0.06 \mathrm{~T})$, where the single-stage GM cooler will be located.

The additional cooling provided by the GM cooler may not solve the problem as to why the heat loads on the first stages of the PT415 coolers are too high. The added cooler will cool down the lead string and reduce the temperature of the magnet shield and intercepts. This should permit LBNL to finish the testing of the second magnet. If the addition of an AL-330 cooler causes the three PT415 coolers to hold the $4 \mathrm{~K}$ heat load with full current in the coils, the magnet can be shipped to Fermilab for magnetic measurement.

The first magnet will be rebuilt with the liquid nitrogen tank on the shield. The connection from the shield to the coolers will be improved. The magnet cold mass has been rebuilt so that there is cooler arrangement is the same as magnet two. A single stage GM cooler at the end of the lead string will also be installed. Adding a fourth PT415 two-stage cooler is being considered for additional $4.2 \mathrm{~K}$ cooling.

The cause of excess heat leak onto the shield and the tops of the HTS leads is being carefully investigated. Improvements on the $4 \mathrm{~K}$ insulation system and around the cold mass supports will be made. The shield insulation will also be improved to reduce the heat leak into the shield and reduce the $\Delta \mathrm{T}$ between the shield and first stages of the coolers.

It is hoped that the things that have been learned from the fabrication and testing of the spectrometer magnets can be applied to the other magnets in MICE. A key lesson is controlling the heat flow to the first-stage of the coolers. PT415 coolers work best when the first-stage is at $55 \mathrm{~K}$.

\section{REFERENCES}

[1] G. Gregoire, G. Ryckewaert, L. Chevalier, et al, "MICE and International Muon Ionization Experiment Technical Reference Document," http://www.mice.iit.edu, 2001.

[2] M. A. Green, S. P. Virostek, W. W. Lau, and S, Q. Yang. "Progress on the MICE Tracker Solenoid," Proceedings of EPAC-06 Edinburgh UK, MICE Note 158, http://mice.iit.edu, (2006)

[3] M. A. Green, "The Effect of Magnetic Field on HTS leads, What Happens if the Power Fails at RAL?" LBNL-62458, MICE Note-162, http://mice.iit.edu, (2007)

[4] M. A. Green and S. T. Wang, "Tests of Four PT415 Coolers in the Dropin Mode," Proceedings ICEC-22 in Seoul Korea, 21 to 25 July 2008, p 105 (2008)

[5] M. A. Green and S. P. Virostek, "The Dimensions and Number of Turns for the Spectrometer Solenoids As-built compared to the Original Design," LBNL-899E, MICE Note 207, http://mice.iit.edu, (2008)

[6] B. Wang, B. Wahrer, C. Taylor, et al, "The Design and Construction of the MICE spectrometer Solenoids", IEEE Transactions on Applied Superconductivity 19, No. 3., p 1348-1351.

[7] X. L. Guo, M. A. Green, L. Wang, et al, "The Role of Quench-back in the Passive Quench Protection Long Solenoids with Coil Subdivision," submitted to IEEE Transactions on Applied Superconductivity 20, No. 3 (this publication), (2010)

[8] S. P. Virostek, M. A. Green, D. Li, et al, "Preliminary Test Results for the MICE Spectrometer Superconducting Solenoids, IEEE Transactions on Applied Superconductivity 19, No. 3, p 1364, (2009)

[9] M. A. Green, H. Wu, L. Wang, et al, "AC Losses in the MICE Channel Magnets Is this a Curse or a Blessing?, LBNL-63804, MICE Note 195, http://mice.iit.edu, (2008)

[10] M. A. Green, "A Design of a Rapid Discharge Varistor System for the MICE Magnet Circuits," LBNL-900E, MICE Note 208, http://mice.iit.edu, (2008) 


\section{DISCLAIMER}

This document was prepared as an account of work sponsored by the United States Government. While this document is believed to contain correct information, neither the United States Government nor any agency thereof, nor The Regents of the University of California, nor any of their employees, makes any warranty, express or implied, or assumes any legal responsibility for the accuracy, completeness, or usefulness of any information, apparatus, product, or process disclosed, or represents that its use would not infringe privately owned rights. Reference herein to any specific commercial product, process, or service by its trade name, trademark, manufacturer, or otherwise, does not necessarily constitute or imply its endorsement, recommendation, or favoring by the United States Government or any agency thereof, or The Regents of the University of California. The views and opinions of authors expressed herein do not necessarily state or reflect those of the United States Government or any agency thereof, or The Regents of the University of California. 